\title{
Arte y coleccionismo en Burgos durante la ocupación francesa
}

\author{
María Dolores Antigüedad del Castillo-Olivares
}

Burgos fue una de las ciudades españolas que más notaron y sufrieron la ocupación por parte de los ejércitos franceses. Su situación geográfica como nudo de comunicaciones entre Francia, Madrid y el resto de la Península la convertian en un importante reducto que era necesario controlar para asegurar el transporte de mercancias y tropas.

En los primeros días del mes de agosto de 1808 Burgos recibió a José Bonaparte, ya proclamado Rey de España, en Bayona, por la Asamblea de Notables que había aprobado la nueva Constitución, que servía de marco legal al cambio dinástico '. De hecho la villa llevaba ocupada por las tropas francesas desde 1807. Escuelas, hospitales y otras dependencias eran utilizadas como cuarteles por el ejército que Napoleón dedicaba a la guerra de Portugal. Estas circunstancias hicieron que Burgos fuera durante seis años una ciudad empobrecida, obligada a mantener a las tropas que la ocupaban. El ejército francés, en especial sus generales, intervino en el gobierno de la población a pesar de los esfuerzos que realizaba el Concejo para mantener la independencia.

\section{SUPRESIÓN DE CONVENTOS Y RECOGIDA DE OBRAS DE ARTE}

Entre las medidas de orden económico que tomó el Gobierno de José I estaba la supresión de conventos de órdenes religiosas y la venta

1 Sobre el reinado de José Bonaparte en España destacan los dos volúmenes publicados por Juan Mercader Riba, José Bonaparte Rey de España. 1808-1813. Madrid 1791 y 1983. 
de sus bienes con objeto de sufragar la deuda pública y ayudar a pagar los gastos que la ocupación militar de España producía.

El 18 de agosto de 1808, el Rey José decretó desde Miranda de Ebro - se había visto obligado a abandonar Madrid después de la derrota en Bailén y fijar su residencia en Vitoria- que se procediera a la venta de los bienes de las Obras Pias y de los conventos con menos de 12 profesos $^{2}$. Como continuación de estas medidas, un decreto del 16 de noviembre de 1808 suprimió un crecido número de conventos burgaleses ${ }^{3}$. Entre los de religiosos fueron suprimidos los siguientes: Benedictinos de San Juan; Benedictinos de San Pedro de Cardeña; los Cartujos de Miraflores; los Jerónimos de Fres del Val, los Jerónimos de San Juan de Ortega, el de Canónigos Premonstratenses de San Cristóbal de Ibens, el de Agustinos Calzados, el de Trinitarios Calzados, el de Dominicos de San Pablo, el de Franciscanos Observantes de San Francisco de Paula, el de Carmelitas Descalzos, el que estaba abandonado de Franciscanos Descalzos de San Pedro Alcántara y el de Mercedarios Calzados. También se suprimia el Monasterio de monjas cistercienses de las Huelgas con sus cuatro comunidades dependientes: la de Capellanes de Huelgas, la de Comendadoras, la de Comendadores y la de Capellanes del Hospital del Rey.

En cuanto a comunidades de monjas fueron suprimidos el convento de las Comendadoras de Calatrava, el de Benedictinas de San José, el de Bernardas de San Bernardo, el de Agustinas Observantes llamadas también Doroteas, el de Agustinas Canonesas de San Ildefonso, el de Franciscas de Santa Clara, el de Franciscas de San Luis, el de Trinitarias, el de Carmelitas Descalzas y el de Franciscas de Vivar del Cid. En total 29 casas religiosas de la ciudad de Burgos y de sus alrededores.

Las propiedades de los conventos, casas y fincas convertidas en Bienes Nacionales pasaron al Estado que las puso en venta. Se vendieron algunas fincas de las comunidades suprimidas y el convento de Santa Clara, el monasterio de Las Huelgas con el monte de la Abadesa y la Cartuja de Miraflores que adquirió el Gobernador Militar de Castilla la Vieja, General Darmagnac ${ }^{4}$.

Las obras de arte y las bibliotecas de los conventos suprimidos se inventariaron y recogieron en depósitos a la espera de darles un fin. Para

\footnotetext{
2 José Mercader Riba, José Bonaparte Rey de España, 1808-1813. Historia externa del reinado. Madrid 1971, pág. 65.

3 Archivo General de Simancas. Gracia y Justicia, leg. 1248.

4 Anselmo Salva, Burgos en la Guerra de la Independencia. Burgos 1913, pág. 59.
} 
la custodia y recogida de los objetos de arte se nombró a don César Gutiérrez de Arce, quien fue reuniendo en el exconvento de San Jerónimo los cuadros y las bibliotecas de las casas enajenadas. El 18 de enero de 1809 se designó al Benedictino de Cardeña, Manuel Núñez, como bibliotecario de la Biblioteca Pública de Burgos a la que se le incorporarían las bibliotecas conventuales recogidas. En los primeros meses de 1809 tanto Arce como Núñez desarrollaron un gran trabajo de custodia y clasificación de cuadros y libros que iban formando nutridos depósitos ${ }^{5}$.

\section{EL GENERAL DARMAGNAC Y LOS CUADROS DE LOS CONVENTOS}

El 25 de enero de 1809 Gutiérrez de Arce escribe al Ministerio del Interior y le expone el malestar y las dificultades que han surgido entre él y el General Vizconde de Darmagnac al intentar recoger la biblioteca y las pinturas que habia en la Cartuja de Miraflores. Allí se habian reunido los mejores cuadros, aunque el depósito general estaba en San Jerónimo. El General le impedía el acceso a la Cartuja basándose en el hecho de que la había comprado y él mismo se ocuparía de su custodia. Arce por su parte opinaba que en la compra no se incluían los muebles y las pinturas. El General relató a Arce cómo habian desaparecido los mejores cuadros de la Cartuja sustraídos por el comandante de las tropas de caballería, que habian ocupado el edificio. Arce le respondió que esto no hubiera sucedido si los cuadros hubiesen estado recogidos en el depósito general.

La carta continuaba relatando que el General había sacado del depósito de San Jerónimo nueve cuadros sin darle recibo por ellos, condición bajo la que se le habían concedido dias antes. La respuesta de Darmagnac al reclamarle el recibo, fue intimidar a Gutiérrez de Arce para que le entregara más cuadros y amenazarle desde su condición de Gobernador Militar; el resultado fue que Arce tuvo que entregarle cinco cuadros más del depósito de San Jerónimo mediante el recibo justificativo pero sin recibir el de los nueve anteriormente sacados. El Genera basaba

5 Archivo General de Simancas. Gracia y Justicia, leg. 1247. 
su negativa en que había enviado muchos más cuadros a San Jerónimo, pero Arce argumentaba que eran lienzos y láminas sin valor tomados de la parroquia que estaba en el castillo.

El propósito de Arce con esta carta era justificarse ante el Ministro salvando su responsabilidad en estos hechos a causa de las amenazas del General, a la vez que enviaba la lista de los catorce cuadros tomados por Darmagnac y solicitaba las órdenes oportunas al respecto. Citamos a continuación el texto completo que remite al Ministro:

"Lista de los catorce quadros que en dos ocasiones ha tomado del depósito de San Geronimo el Sr. Governador de Castilla La Vieja Mr. Darmagnac, a saber los nuebe primeros una vez, y otra los cinco restantes, haviendo dado recibo solo de estos ultimos.

En tabla.-Dos quadros de franco. Pourbus con la firma del Autor señalado el año de $15 \ldots$ que representa el uno la Visitacion, y el otro una Virgen sentada en una silla adornada de rubies, esmeraldas y tienen de alto dos pies y medio y de ancho dos pies cada uno: se hallaban en la Sacristia del Convto. de P.P. Carmelitas descalzos.

En Lienzos.-Tres quadros grandes de la escuela de los Basanes (según Mr. Denon Director del Museo Napoleon en Paris). Con muchas figuras apaisados dos de ellos; se trajeron de las Huelgas.

En Tabla.-Tres quadros pequeños de la escuela de Alberto Durero que representan pasos de la Pasion de Cristo; y se trajeron con otros mas que se hallan en el deposito de San Geronimo, de la sacristia de la capilla del Cristo de la Trinidad.

En Tabla.-Un quadro pequeño que representa el transito de la Virgen con muchas figuras, se trajo de las Monjas Carmelitas.

En Tabla.-Un quadro grande con sus dos puertas en el que se representa San Sebastian, y en las puertas por lo interior a San Roque la una, y la otra otro Sto. desnudo; y en el exterior de las puertas hay retratos, executado todo segun el estilo de Durero: y se hallaban en la Iglesia de P.P. Trinitarios.

En Tabla.-Las dos puertas de otro quadro que representa la venida del Espiritu Sto. y estaba en el claustro de la Trinidad, hallandose el quadro actuaimente en San Geronimo; y las puertas que contienen varios retratos según el estilo de Durero pero de mucho mérito, son las que tomó el Governador Mr. Darmagnac.

Nota: Acerca del mérito de estos quadros pueden verse los tomos 12 de Dn. Antonio Ponz, y $1 .^{\circ}$ del Sr. Bosarte" ${ }^{6}$.

6 Tanto la carta como la lista de cuadros pertenecen al Archivo de Simancas, Gracia y Justicia, leg. 1247. 
El 2 de febrero, el Ministro del Interior escribia a Gutiérrez Arce que había quedado enterado del hecho de que el General Darmagnac había extraído cuadros y pinturas de la Cartuja y del Colegio de San Jerónimo, pero no le transmitía orden alguna al respecto.

\section{LOS CUADROS ELEGIDOS POR DARMAGNAC}

Como muy bien señalaba don César Gutiérrez de Arce, los cuadros que Darmagnac tomó de los depósitos habían sido mencionados y elogiados por Ponz y Bosarte en sus respectivas obras al referirse a Burgos.

Isidoro Bosarte había visto dos cuadros en la Sacristía del convento de los P.P. Carmelitas Descalzos, que se creían de Gaspar Becerra y que sin embargo estaban firmados "Fco. Pourbus $f$. 15.." y para apoyar su valoración cita el libro de Joaquín Sandrat: Academia (libro III, capítulo II). En uno de ellos se representa a la Virgen María con el Niño en brazos, sentada en una silla guarnecida de perlas y rubíes, "todo muy definido y concluido con mucho gusto y buenas partidas». La otra pintura es una Visitación; cada tabla tenía dos pies escasos de ancho ?.

Por su parte, Antonio Ponz había visto en la iglesia del convento de los P.P. Trinitarios algunos retablos de estilo alemán o de Durero. En uno de estos se representaba a San Sebastián y en las puertas dos Santos de igual mérito. Opina que "son obras muy dignas que se conserven o por mejor decir de que no se maltraten, pues ellas mismas se conservan como si se acabasen de pintar: tal es la viveza de los colores, y la prolijidad de la execución que da mucho gusto al considerarlo" ${ }^{8}$.

También en el claustro del convento de Trinitarios, había visto Ponz una buena pintura que representaba la Venida del Espíritu Santo y cuyas puertas eran retratos de personas arrodilladas, "todo ejecutado con grandeza en el estilo alemán"; al parecer se hicieron a costa de D. Antonio del Río, Señor de Lleidala y de Artselaer, cerca de Amberes, del Consejo

7 Isidoro Bosarte, Viaje artístico a varios pueblos de España. Madrid 1804. Ed. Facsimil, Madrid 1978, pág. 325.

8 Antonio Ponz, Viaje de España. Madrid 1788, tomo XII, pág. 83. 
de Hacienda de Carlos II; eran, a juicio de Ponz, obra de gran mérito sobre todo en la parte de los retratos ${ }^{9}$.

Ponz también había contemplado en la Capilla del Cristo de Burgos en la iglesia de los Trinitarios, cinco pinturas de estilo alemán; sin duda a este conjunto pertenecen las tres sobre la Pasión del Señor que coge el General Vizconde Darmagnac.

El convento de la Trinidad era uno de los edificios más notables de Burgos y también de los más antiguos. Se levantó en 1207 a costa de Alfonso VIII para San Juan de Mata. Su iglesia tenía una gran riqueza en alhajas y ornamentos. El conjunto se había edificado en sucesivas épocas y tenía una bella fachada oeste de estilo gótico florido, con abundancia de cresterías, estatuas y blasones. El convento desapareció durante la guerra de la Independiencia y la imagen del llamado Cristo de Burgos, que tenía alli su capilla, se trasladó a la Iglesia de San Gil ${ }^{10}$. Después de la contienda, los religiosos refundaron la Capilla del Cristo en 1815 bajo la advocación de San lidefonso y colocaron de nuevo la imagen del Cricificado ${ }^{11}$.

\section{LA COLECCIÓN DEL VIZCONDE DARMAGNAC}

Juan Bartolomé Claudio Santos Darmagnac nació en Toulouse en 1766 y es un notable representante del ejército de Napoleón; su nombre está escrito en el Arco de Triunfo de la Estrella de París. Fue ascendiendo en el ejército a la vez que avanzaban las campañas del Emperador. En 1791, siendo capitán, pasó a Italia hasta 1797 y después a Egipto donde ascendió a General de Brigada. Desde 1808 intervino en las campañas de España conquistando Pamplona y combatiendo en Medina de Ríoseco; estos actos le valieron el grado de General de División. Fue Gobernador Militar de Galicia, Castilla la Vieja, La Mancha y Cuenca. En 1815 con la caída de Napoleón y los cambios políticos en Francia decide retirarse a Burdeos y en esta ciudad murió el 1 de noviembre de 1855 a edad avanzada.

9 Antonio Ponz, obra citada, tomo XII, pág. 86.

10 Vicente Garcia y Garcia, Guia del viajero en Burgos. Burgos 1867.

$"$ L. Huidobro Serna, "El arte isabelino en Burgos y su provincia". Boletín de la Institución Fernán González. Burgos, año XXX, n. ${ }^{\circ} 116,1951$, pág. 556. 
Como otros generales del Imperio fue reuniendo una notable colección de obras de arte, no importándole demasiado la forma de conseguir las piezas y valiéndose de su posición de fuerza en los países ocupados. Los cuadros que integraban su colección procedían la mayor parte de España, donde tuvo ocasión durante varios años de conocer e ir reuniendo obras de arte de notable mérito. Su colección no es conocida en su totalidad, las piezas se han ido reconociendo al salir a la venta y al publicarse su testamentaría, pero no existe un catálogo que le muestre como afamado coleccionista, como es el caso del Mariscal Soult, Duque de Dalmacia ${ }^{12}$.

Su actitud al llegar a Burgos fue visitar iglesias y conventos tratando de hacerse con piezas importantes que fueran de su agrado. Se sabe que trató, a finales del mes de enero de 1809, de que el Cabildo Catedralicio le regalase un cuadro de la Magdalena que se guardaba en la Capilla del Condestable de la Catedral burgalesa, el lienzo estaba tradicionalmente atribuido a Leonardo de Vinci, aunque investigaciones posteriores lo atribuyen a Giovanni Pietro Ricci (Fig. 1). Darmagnac justificaba esta petición en el hecho de haber preservado a la Catedral del saqueo sufrido por la ciudad el 10 de noviembre de 1808. El Cabildo le respondió que no podía disponer del cuadro por ser propiedad del patrono de la capilla, el Duque de Frías, embajador en Paris en aquellos momentos, por lo que el General no insistió más sobre el particular ${ }^{13}$. Más suerte tuvo Darmagnac en la iglesia de San Gil, cuyo párroco le regaló una Purisima Concepción que estaba en una capilla del convento de San Francisco, como agradecimiento por la guardia que puso en el templo, aunque los mismos curas tuvieron que pagarla ${ }^{14}$.

Las obras que fue vendiendo hasta su muerte son notables, además de por su calidad indudable, por ser la mayor parte de ellas piezas en tabla del siglo XV y principios del XVI. Llama la atención su interés por este tipo de arte, ya que se trata de obras de artistas apenas documentados en aquellos momentos y que, en ocasiones, han pasado por varias atribuciones diferentes a causa del desconocimiento que sobre ellas existía. Esta actitud no es diferente a la mantenida por el ejército napoleónico en general, que llevó a cabo una enorme labor de confiscación de obras de arte en todas sus campañas, desde Italia a Egipto, de España a los

12 El Mariscal Soult poseía una notable colección de cuadros españoles sobre todo de Murillo, bien conocidos y catalogados por los expertos. Catalogue de la galerie du Maréchal Soult, duc de Dalmacie. París 1852.

13 Anselmo Salva, obra citada, pág. 56.

14 SALVÁ, obra citada, pág. 97. 
Países Bajos. Estas piezas después de 1814 se dispersaron y fueron a parar a los Museos europeos, en ocasiones alejados de su lugar de origen dando a conocer obras y estilos hasta entonces poco conocidos o ignorados ${ }^{15}$.

El Museo de Berlín guarda en la actualidad dos obras procedentes de la colección Darmagnac que a través de las sucesivas ventas han llegado a esta institución. Se trata del retablo de la Vida de la Virgen y del Tríptico de la Vida de San Juan Bautista, obras ambas de Roger van der Weyden.

El retablo de la Vida de la Virgen o tríptico de Miraflores (Catálogo Museo de Berlín n. ${ }^{\circ}$ 534) era el altar portátil que Juan II de Castilla donó a la Cartuja burgalesa y en cuya sacristía lo había visto Ponz dedicándole un comentario elogioso (Figs. 2 y 3). Desde 1809 perteneció al General Darmagnac hasta que lo vendió el 2 de julio de 1836 en Christie's de Londres; después de ventas sucesivas pasó a la colección del Rey Guillermo II de Holanda y de ésta al Museo de Berlín en $1850^{16}$.

El tríptico de la Vida del Bautista (Catálogo Museo Berlín n. ${ }^{\circ} 534 \mathrm{~B}$ ) procede también de la Cartuja de Miraflores de donde fue sacado por Darmagnac (Figs. 4 y 5); como el anterior fue comprado por Guillermo II de Holanda, menos una de sus tablas que perteneció a una colección inglesa, de donde pasaron en 1850 a Berlín ${ }^{17}$.

Hay una serie de tablas que sin duda proceden de la Cartuja de Miraflores que han sido objeto de polémica entre los estudiosos de la pintura hispano-flamenca. Se trata de una serie de escenas de la vida de San Juan Bautista que integraban, según la opinión de los expertos, un retablo que vio Ponz en el Coro de Legos de la Cartuja de Miraflores. Son el "Festín de Herodes", hoy en el Museo Mayer ven der Berg de Amberes, el "Bautismo de Cristo" de la colección Jordán de Urries de Madrid, la "Degollación de San Juan Bautista» de Ginebra y el "Nacimiento de San Juan" del Museo de Cleveland (Ohio, EE.UU.), todas atribuidas a Juan de Flandes según recientes publicaciones dedicadas al tema. La única de ellas que tenemos seguridad de que pertenecía a la

15 Sobre estos aspectos de la invasión napoleónica tiene un gran interés el artículo de Dorothy MACKAY QUYNN: "The Art Confiscations of the Napoleonic Wars", The American Historical Review, vol. L, n. ${ }^{\circ} 3$, abril, 1945, pág. 437-460.

16 Elisa Bermejo, La pintura de los primitivos flamencos en España. Madrid 1980, tomo I, pág. 102-103.

17 Elias TORmo Y MONzo, “Sobre algunas tablas hispano-flamencas sacadas de Castilla la Vieja". Boletín de la Sociedad Castellana de Excursiones, 1907-1908, pág. 546-558. 
colección Darmagnac es la tabla de Amberes "El festín de Herodes", ya que le fue comprada al General por el Conde Tanneguy Duchâtel (18031867), ministro de Luis Felipe de Francia, junto con una Virgen de Memling y dos obras de Antonio Moro, hoy las tres obras en el museo del Louvre; "El Festín" pasó luego a la colección Mayer van der Berg.

No vamos a entrar en la polémica de si las tablas son originales de Juan de Flandes, si proceden o no de Miraflores o si formaban parte del retablo que vio Ponz: lo que nos interesa es el hecho de que la primeramente mencionada pertenecía al General Darmagnac ${ }^{18}$. Por nuestra parte pensamos - dado que la Cartuja de Miraflores sufrió un importante expolio y que sirvió como almacén de obras recogidas en otros conventos burgaleses, como ponía de manifiesto la documentación comentada con anterioridad-, que es posible que todas ellas procedan de Burgos, aunque no necesariamente tienen por qué ser de la misma Cartuja, muy bien podrian haber sido llevadas de otro lugar y alli almacenadas.

El Museo del Louvre posee una tabla atribuida a Memling conocida como la Virgen de Jacques Floreins (Catálogo Museo Louvre n. ${ }^{\circ}$ 2026) que procede también de la colección Darmagnac. Esta pintura fue legada al Museo por la viuda del Conde Duchâtel en 1878. La tabla representa a la Virgen y al Niño entre Santiago y Santo Domingo con los donantes arrodillados a sus pies ${ }^{19}$. El donante Jacques Floreins murió en 1489 o 1490 y estuvo casado con una española. Después de su muerte el cuadro pasó a España, por lo que no tiene nada de extraño que proceda de Burgos en virtud de las grandes relaciones que existian entre la ciudad castellana y los Paises Bajos en el siglo xv.

Todas estas obras que hemos ido comentando salieron a la venta antes de la muerte del General; quizá se vio obligado a venderlas por necesidades económicas. A la vez que se ponia a la venta en Londres el retablo de Miraflores, se subastaba también un bodegón de López Enguidanos, un Aloriso Cano, un Ribera, una Virgen con el Niño de Mi-

18 Hay una polémica recogida en diferentes publicaciones entre los que defienden teorias distintas sobre el posible origen del retablo, su composición, autoría, etc. Las publicaciones más recientes son el trabajo de Jozef DE COO y Nicole REYNAUD, "Origen del retablo de San Juan Bautista atribuido a Juan de Flandes". Archivo Español de Arte, 1976, n. ${ }^{\circ}$ 206, pág. 125-144 y la Tesis Doctoral de Pilar Silva MAroto, Pintura hispano-flamenca castellana; Burgos y Palencia. Madrid, Ed. Universidad Complutense, 1988, pág. 329, que se inclina por una posición de síntesis al creer que el retablo que citó Ponz en Miraflores es obra de Juan de Flandes y estaba formado por las tablas citadas y en la actualidad dispersas.

19 La Peinture au Musée du Louvre, Écoles Etrangeres. Tomo II, París 1929, pág. 18. 
chel Coxie y una "Magdalena en el desierto" de Murillo, al parecer procedentes de El Escorial y regalo de José I que alcanzó un precio de 230 libras ${ }^{20}$. Como puede verse por lo subastado en esa ocasión, Darmagnac poseía una amplia variedad de obras españolas.

Después de la muerte del General se tasó e inventarió el resto de su colección ante el notario que se ocupó de la testamentaría. Constaba de 53 cuadros de variados autores: Holbein, Ribera, Mengs, Orrente, Alonso Cano (una "Coronación de la Virgen" tasada en 2000 francos) y otras varias obras de pintores españoles, además de algunos italianos como Jordán, Castiglione o el Beato de Afiesole (¿Fray Angélico?). Destaca, no obstante, la presencia de una Virgen con el Niño y una Visitación, catalogadas como obras de Michel Coxie (1499-1592), tasadas en 1000 y 500 francos respectivamente, precio elevado en comparación con el resto; estas obras han despertado nuestro interés, ya que forman pareja y podrían identificarse como la Virgen y la Visitación sacadas por el General del depósito de San Jerónimo en Burgos y que Bosarte había atribuido a Francisco Pourbus (1545-1581), ambas procedian de la Sacristía del convento de los Padres Carmelitas Descalzos. La diferencia de atribución podría deberse al escaso conocimiento sobre estos artistas y a tener unas caracteristicas similares: una técnica de origen flamenco y un conocimiento de los manieristas italianos, sin olvidar la coincidencia cronológica $^{21}$.

El 19 de febrero de 1857 se vendió en París un resto de la colección Darmagnac, en ella sólo aparecen tres obras de pintores españoles, sin duda a causa de una nueva catalogación ${ }^{22}$. No se trata de trípticos ni pinturas del siglo xv. El precio más elevado lo obtuvo un retrato del Duque de Alburquerque pintado por Alonso Sánchez Coello, regalado al General por el Rey José Bonaparte ${ }^{23}$. Ni el catálogo de la testamentaria,

20 Sobre la manera de formarse la colección Darmagnac trata el artículo de S. REl$\mathrm{NACH}$, “Jactus Lapilli». Revue Archeologique, 1927, pág. 121-137. El título hace alusión a la manera como el General Darmagnac tomó posesión de Mirá́lores: lanzar una piedra desde la puesta de la Cartuja al interior pues con este rito se "consacrait le droit absolu de disposer de tout». La noticia curiosa está sacada de las memorias del General Thiébault que sustituyó a Darmagnac en Burgos a principios de 1809.

21 La relación de las obras de arte que Darmagnac poseia a su muerte está recogida por Reinach en el artículo citado anteriormente, pág. 136-137.

22 Ilse HEMPEL LIPSCHUTZ, La pintura española y los románticos franceses, Madrid, 1988, pág. 365.

${ }_{23}$ El tema de las recompensas de José Bonaparte a sus generales en forma de obras de arte to he tratado en mi Tesis Doctoral: José Bonaparte y el patrimonio artistico de los conventos madrileños, Madrid, Ed, Universidad Complutense, 1987, pág. 278-314. 
ni en esta venta podemos identificar con claridad las obras sacadas de Burgos, en especial los cuadros procedentes de las Huelgas.

\section{LA FORTUNA DE LA PINTURA HISPANO-FLAMENCA}

La Guerra de la Independencia causó notables pérdidas en iglesias y conventos de toda España y por supuesto de Burgos, de donde desaparecieron un buen número de cuadros y objetos de culto. Lo sucedido con el General Darmagnac no pasaría de ser un acontecimiento bélico más, si no nos hubiera sorprendido la clase de pintura que saca de la ciudad. Se trata, en su mayor parte, de tablas, como pone de manifiesto el comisionado Gutiérrez de Arce, además son obras escasamente conocidas a las que Ponz y Bosarte mencionan de pasada. Estamos, pues, ante un coleccionista particular; no elige cualquier cosa, sino que tiene un fino olfato ante piezas poco valoradas o escasamente conocidas.

Una prueba de esta ausencia de interés hacia dichas obras, está en las listas de objetos desaparecidos a causa de la guerra, que hicieron conventos e iglesias en 1814 a petición del Gobierno. En el caso de Burgos las relaciones presentadas cargan las tintas en las piezas de metales preciosos que habían perdido y que por su valor material eran presas codiciadas por los saqueadores. Tan sólo en la Cartuja de Miraflores se menciona la falta del altar portátil de Juan II y cinco tablas pintadas con la vida y muerte del Bautista, obras de Juan Flamenco; el resto reclamado son cuadros de época barroca ${ }^{24}$. En todas las relaciones escasean las referencias a estas modestas tablas hispano-flamencas o primitivas importadas de Flandes y que eran abundantes en las iglesias burgalesas. Juan Antonio Gaya Nuño, en su libro Pintura Europea perdida por España, comenta la enorme cantidad de pintura flamenca sacada de conventos de Burgos, Palencia, Segovia, Ávila y Soria; lo mismo dice sobre los primitivos flamencos que aparecieron en el mercado artístico europeo desde 1813, y aún más, después de 1835 tras la desamortización de Mendizábal. Al ser la pintura menos conocida, tan sólo vagas referencias en las obras de Ponz y Bosarte, se hacia dificil saber su procedencia.

24 Vicente García y Garcia, obra citada, pág. 241. 
Los ejércitos napoleónicos sivieron de transmisores de este tipo de pintura, ya que la apropiación de obras de arte en los Países Bajos y en otros lugares, su posterior traslado a París y la dispersión que produjo su venta, hizo que estos estilos fueran más familiares a partir de 1830 . El Museo Napoleón fue un vehículo para el conocimiento de obras y artistas alejados de los ideales académicos y de estilos anteriores a $1500^{25}$. No podemos olvidar que en el Museo Napoleón estaba la Virgen del Canciller Rolin de Jan van Eyck.

A comienzos del siglo $x \mid x$, sobre todo en Alemania e Inglaterra, se aprecia un interés por las obras de los llamados primitivos, nombre que recibieron de los autores románticos, para los que estas pinturas tenian una pureza anterior al humanismo, por ello es en estos años cuando se comienzan a reunir en colecciones. No obstante, todavía en la Galería de Luis Felipe en Paris, que se inauguró en 1838, la pintura española primitiva tenía un escaso interés. Para esta muestra de pintura española el Barón Taylor compró un «Entierro de Cristo" de Jaime Huguet, hoy conservado en el Museo del Louvre, que tuvo que retirarse al no considerárselo digno de colgar en esta exposición ${ }^{26}$.

La documentación que presentamos sobre las actividades de Darmagnac en Burgos, quizá sirva para tratar de identificar las obras que salieron de Burgos y que formaban parte de su patrimonio cultural. Los sucesivos traslados y ventas que pueden haber sufrido, convierten su localización en una tarea ardua.

25 François Bonoit, L'Art français sous la Revolution et l'Empire. París 1897, pág. 12430 , en estas páginas se trata la libertad que se manifiesta en el gusto artistico durante el Imperio.

26 Jeannine BÃtICle y Cristina MaRinas, La Galerie espagnole de Louis-Philippe au Louvre. París 1981, pág. 23. 


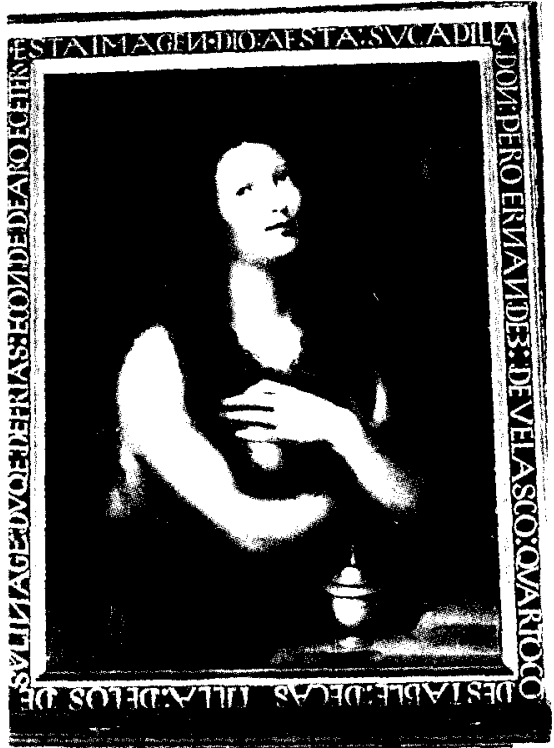

Fig. 1. Gian Pietro Ricci: Magdalena Penitente (Capilla del Condestable, Catedral de Burgos).

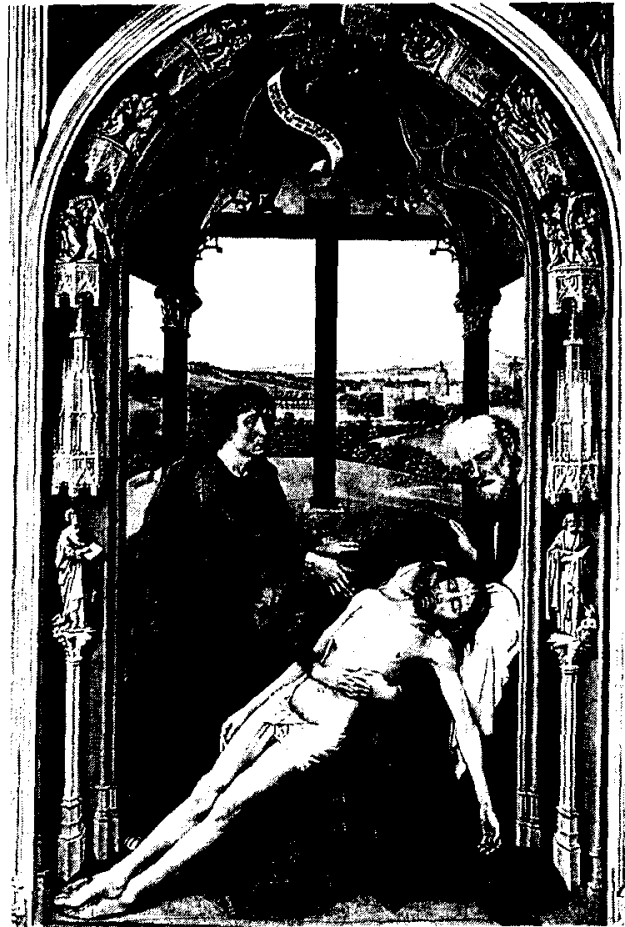

Fig. 3. Roger van der Weyden: Triptico de Miraflores. Piedad (tabla central). Museo de Berlín.

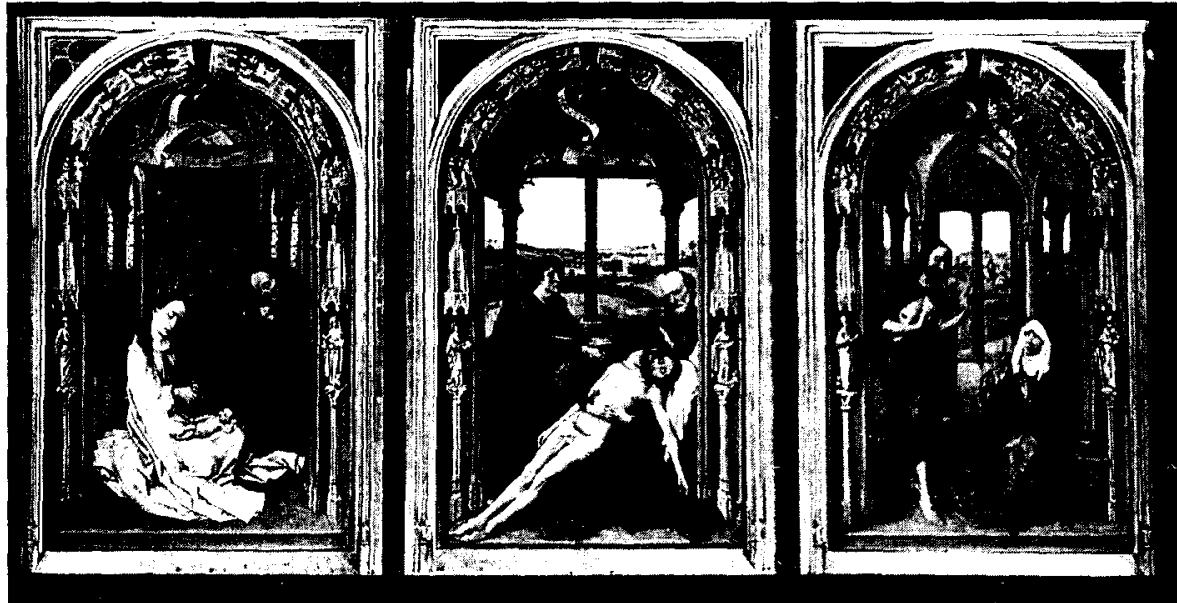

Fig. 2. Roger van der Weyden: Triptico de la Virgen o triptico de Miraflores (Museo de Berlin). 


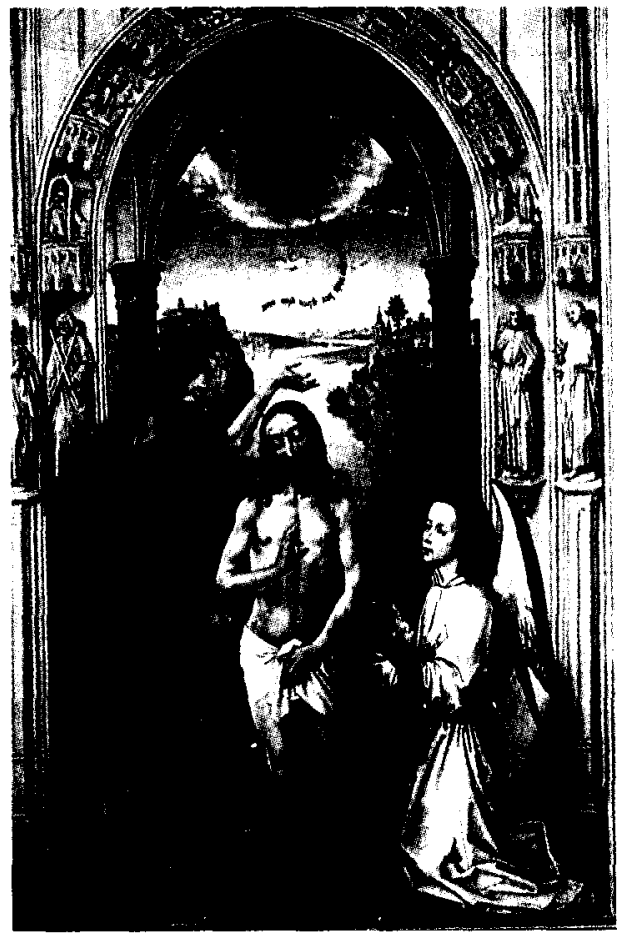

Fig. 4. Roger van der Weyden: Tríptico de San Juan Bautista. Bautismo de Cristo (tabla central). Museo de Berlín.

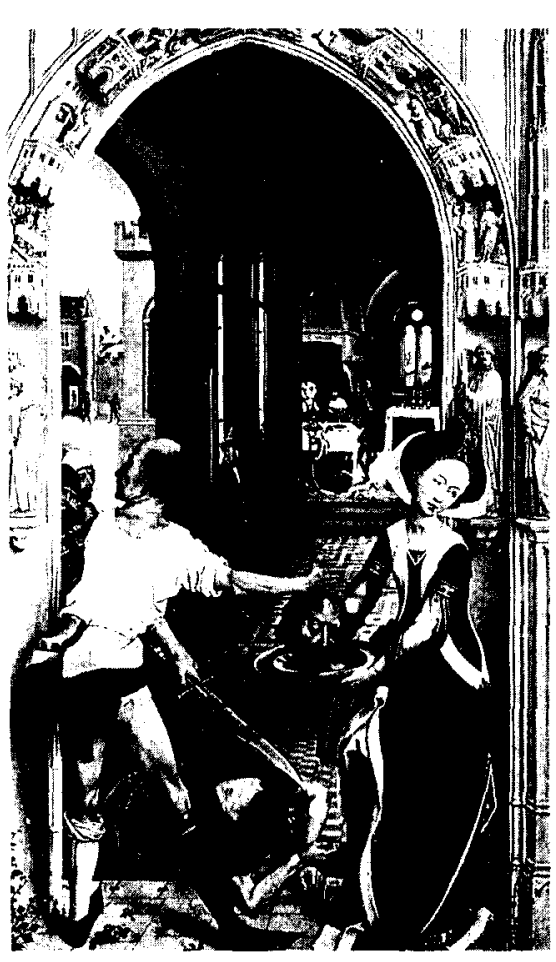

Fig. 5. Roger van der Weyden: Triptico de San Juan Bautista. Degollación del Bautista (tabla derecha). Museo de Berlín. 